\title{
Isolation and characterization of novel human short-chain dehydrogenase/reductase SCDR10B which is highly expressed in the brain and acts as hydroxysteroid dehydrogenase ${ }^{\star}$
}

\author{
Chaoqun Huang ${ }^{1,2}$, Bo Wan ${ }^{1}, B_{0} G_{a o}^{3}$, Saiyin Hexige ${ }^{1}$ and Long $\mathrm{Yu}^{1 凶}$ \\ ${ }^{1}$ State Key Laboratory of Genetic Engineering, The Institute of Genetics, Fudan University, Shanghai, People's \\ Republic of China; ${ }^{2}$ Department of Physiological Sciences, Oklahoma State University, Stillwater, USA; \\ ${ }^{3}$ Department of Phamacology, Soochow University, Suzhou, People's Republic of China
}

Received: 09 February, 2009; revised: 14 April, 2009; accepted: 28 April, 2009

available on-line: 12 May, 2009

\begin{abstract}
Hydroxysteroid dehydrogenase belongs to the subfamily of short-chain dehydrogenases/reductases (SDR), and 11- $\beta$-hydroxysteroid dehydrogenase catalyzes the interconversion of inactive glucocorticoids (cortisone in human, dehydrocorticosterone in rodents) and active glucocorticoids (cortisol in human, corticosterone in rodents). We report here the cloning and characterization of a novel human SDR gene SCDR10B which encodes a protein with similarity to 11 $\beta$-hydroxysteroid dehydrogenase 1. SCDR10B was isolated from a human brain cDNA library, and was mapped to chromosome 19p13.3 by browsing the UCSC genomic database. It contains an ORF with a length of $858 \mathrm{bp}$, encoding a protein with a transmembrane helix and SDR domain. Its molecular mass and isoelectric point are predicted to be $30.8 \mathrm{kDa}$ and $10.3 \mathrm{kDa}$, respectively. SCDR10B protein is highly conserved in mammals and fish. Phylogenetic tree analysis indicated that SCDR10B stands for a new subgroup in the 11ß-hydroxysteroid dehydrogenase family. Northern blot analysis showed that $S C D R 10 B$ was highly expressed in brain, and a strong expression signal was detected in hippocampal neurons by immunohistochemical analysis. RT-PCR and immunohistochemical analysis showed that $S C D R 10 B$ was up-regulated in lung-cancer cell lines and human lung cancer. SCDR10B can catalyze the dehydrogenation of cortisol in the presence of NADP ${ }^{+}$, and therefore it is a hydroxysteroid dehydrogenase.
\end{abstract}

Keywords: clone, hydroxysteroid dehydrogenase, brain, expression pattern

\section{INTRODUCTION}

The short-chain dehydrogenase/reductase (SDR) family is a very large family of enzymes, most of which are $\mathrm{NAD}^{+}$or $\mathrm{NADP}^{+}$dependent oxidoreductases (Kallberg et al., 2002). So far more than 3000 members from all forms of life are found in protein or nucleic acid databases. Members of this family consist of 250-350 amino-acid residues (Jornvall et al., 1995). All the members of the family only have a residue identity level of typically $15-20 \%$, but two motifs are highly conserved in this superfamily (Oppermann et al., 1997; Filling et al., 2002): one is the GXXXGXG motif related to binding cofactor $\operatorname{NAD}(\mathrm{P})(\mathrm{H})$, the other is the $\mathrm{YXXXK}$ related to its catalytic activity.

\footnotetext{
$\square$ Corresponding author: Long Yu, State Key Laboratory of Genetic Engineering, The Institute of Genetics, Fudan University, Handan Road 220, Shanghai 20043, People's Republic of China; tel.: 86-21-65642944; fax: 86-21-65643250; e-mail: longyu@fudan.edu.cn

^ The sequence data of SCDR10B and its orthologs have been submitted to the GenBank database under accession numbers: AY634366, AY554048, AY554049, AY578179, AY578810, AY578812, AY578181, DQ862062, DQ862061, DQ832430.

Abbreviations: BLAT, BLAST-like alignment tool; EST, expressed sequence tag; 11 $\beta$-HSD1 (HSD11B1), 11 $\beta$-hydroxysteroid dehydrogenase 1; 11 -HSD2 (HSD11B2), 11 -hydroxysteroid dehydrogenase 2; GR, glucocorticoid receptor; IPTG, isopropyl $\beta$-D-thiogalactosidae; MR, mineralocorticoid receptor; LB, Luria-Bertani medium; SABC, streptavidin-biotin-peroxidase complex; SDR, short-chain dehydrogenase/reductase family; SCDR, short-chain dehydrogenase/reductase; ORF, open reading frame; $\beta$-MG, $\beta$-microglobulin.
} 
SDR family members participate in the metabolism of steroids, prostaglandins, retinoids, aliphatic alcohols and xenobiotics. Hydroxysteroid dehydrogenase, a subfamily of SDR that includes 17 $\beta$-hydroxysteroid dehydrogenase, $11 \beta$ hydroxysteroid dehydrogenase and $3 \beta$-hydroxysteroid dehydrogenase, contributes to the metabolism of steroids. 11ß-hydroxysteroid dehydrogenase catalyzes the interconversion of inactive glucocorticoids (cortisone in human, dehydrocorticosterone in rodents) and active glucocorticoids (cortisol in human, corticosterone

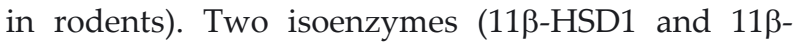
HSD2) have been identified. 11 $\beta$-HSD1, also called "liver" type 11 $\beta$-hydroxysteroid dehydrogenase acts mainly as a NADPH-dependent cortisone reductase (Stewart et al., 1999). The 11ß-HSD1 gene is located at chromosome 1q32.2, and is highly expressed in the liver, adipose tissue, bone and the brain (Ricketts et al., 1998; Brereton et al., 2001); it plays an important role in human obesity and insulin resistance (Stewart et al., 1999; Tomlinson et al., 2000; Wolf, 2002). $11 \beta-H S D 2$, the "kidney" type 11 $\beta$-hydroxysteroid dehydrogenase, acts as an $\mathrm{NAD}^{+}$-dependent cortisol dehydrogenase. The 11ß-HSD2 gene is located at chromosome 16q22, it is highly expressed in classical mineralocorticoid-selective target tissues such as kidney, colon and sweat glands (Diaz et al., 1998; Brereton et al., 2001; Audige et al., 2002; Kataoka et al., 2002). 11ß-HSD2 is linked to hypertension and apparent mineralocorticoid excess syndrome (Kotelevtsev et al., 1999; Krozowski et al., 1997; Lin-Su et al., 2004).

Active glucocorticoids (cortisol, corticosterone) and mineralocorticoids (aldosterone) play their roles through binding to their receptors (glucocorticoid receptor, GR; mineralocorticoid receptor, MR), and subsequently regulating the transcription of target genes (Diaz et al., 1998; De Kloet et al., 2000; Rabbitt et al., 2002). Cortisol is the main circulating glucocorticoid in the human and it is mainly synthesized and secreted in the zona fasciculata of adrenal gland. Aldosterone is the principal mineralocorticoid in the human and is mainly synthesized and secreted from the zona glomerulosa of the adrenal gland. The amount of glucocorticoids and mineralocorticoids available to activate GR and MR is not only dependent on the circulating levels but also on prereceptor metabolism by $11 \beta-H S D 1$ and $11 \beta-H S D 2$ occurring intracellularly (Rabbitt et al., 2002). 11ßHSD1 can activate glucocorticoids and make them access GR. The level of circulating glucocorticoids is 3 orders of magnitude higher than that of aldosterone ( $1 \mu \mathrm{M}$ versus $1 \mathrm{nM}$, respectively), but glucocorticoids and aldosterone have an equivalent affinity for the mineralocorticoid receptor MR. Under normal physiological conditions glucocorticoids are expected to occupy the MR and regulate gene transcription, instead of aldosterone. However, the enzyme $11 \beta$ HSD2 is coexpressed with the mineralocorticoid receptor, and unlike glucocorticoids, aldosterone does not react with $11 \beta$-HSD2. Thus, aldosterone can gain access to MR in epithelial and non-epithelial tissues and regulate transcription of genes that contribute to the mineralocorticoid response (Funder, 2005).

It was previously reported that GR and MR are expressed in the brain (Diaz et al., 1998; De Kloet et al., 2000; Poletto et al., 2006). In fact, the rat mineralocorticoid receptor was actually first cloned from brain cDNA (Patel et al., 1989). In addition, some brain areas can locally produce aldosterone. MR sites, and their encoding mRNA, are highly expressed in the hippocampus (Watzka et al., 2000) and lateral septum, and in several brain stem nuclei, such as the motor XI nucleus (Arriza et al., 1988). $11 \beta-H S D 1$ is expressed in the brain, with the highest levels found in the cerebellum, hippocampus, cortex, pituitary and hypothalamus, but its main function is activating glucocorticoids. 11 $\beta-H S D 2$ expressed in human fetal brain acts to protect the developing nervous system from the deleterious consequences of glucocorticoid overexposure, but $11 \beta$-HSD2 is barely expressed in the human adult brain. It is not understand why barely expressed $11 \beta$-HSD2 is sufficient to inactivate glucocorticoids and thereby adjusting the aldosterone to the MR and why it is sufficient to prevent the GR from becoming overactivated by cortisol in the human brain. The mechanism for aldosterone-specific actions in the brain becomes difficult to explain. It is still unknown whether another $11 \beta$-hydroxysteroid dehydrogenase is switched on in human adult brain in place of the switched off $11 \beta$ HSD2. The possibility of additional tissue-specific $11 \beta$-HSDs has been discussed for many years. However, such isoforms have not yet been characterized at either the biochemical or the molecular level. So we are interested in investigating whether additional brain-specific or more generalized $11 \beta$-HSD isoforms exist.

In the present study, the reported coding sequence of human 11ß-HSD1 was submitted for a TBLASTN search of GenBank, which allowed us identify ESTs that were shown to have no homology to known 11ß-hydroxysteroid dehydrogenase. A surprising finding is that many identified ESTs are transcribed from the brain. The new ESTs were assembled into a cDNA which encodes a protein with an integral ORF covered human HSD11B1 whole coding region. The cDNA was further cloned from the brain cDNA library and verified by sequencing. The cDNA was submitted to GenBank with the name SCDR10B and was given accession number AY268352. Northern blotting indicated that $S C D R 10 B$ is highly expressed in the brain, and a strong expression signal was detected in the hippoc- 
ampal neurons by immunohistochemical analysis. RT-PCR and immunohistochemical analysis showed that SCDR10B was upregulated in lung cancer cell lines and human lung cancer. SCDR10B can catalyze the dehydrogenation of cortisol in the presence of $\mathrm{NADP}^{+}$, therefore it is a hydroxysteroid dehydrogenase.

\section{MATERIALS AND METHODS}

Cloning of SCDR10B. TBLASTN GenBank searches with the reported coding sequence of human 11ß-HSD1 sequence (GenBank accession number NP_861420) allowed us to identify many new ESTs which were shown to have no homology to known HSD11B1. The new ESTs were assembled into a contig. To verify the sequence of the contig, primers of SCDR10B-up (5'-AGTGGGGGAAACTGAGGCCTGAG-3' corresponding to nucleotides 183-205) and SCDR10B-down (5'-GTTCTGGCTCCAGGGACAGTTGG-3' corresponding to nucleotides 1130-1152) were designed and synthesized (Shenggong BioTech, Com. China). PCR was performed with $S C D R 10 B$ primers, and a human brain cDNA library (Clontech Co. Ltd) was used as a template. The PCR conditions were: $94^{\circ} \mathrm{C}$ for $5 \mathrm{~min}, 35$ cycles of $45 \mathrm{~s}$ at $94^{\circ} \mathrm{C}, 45 \mathrm{~s}$ at $58^{\circ} \mathrm{C}, 100 \mathrm{~s}$ at $72^{\circ} \mathrm{C}$, followed by a final extension of $5 \mathrm{~min}$ at $72^{\circ} \mathrm{C}$. The PCR product was subjected to T-A cloning and sequencing.

In silico analysis. To determine the mapping information, the sequence of $S C D R 10 B$ was submitted for genomic searching at http://genome.ucsc.edu. BLAST and TBLASTN tools (http://www.ncbi.nlm. nih.gov) were applied for identifing the orthologs of SCDR1OB in different species. The SMART tool was used for domain searching (http://smart.emblheidelbeg.de), and the Vector NTI package (Informax, Co. Ltd) for protein molecular mass prediction. GeneDoc software was used for sequence alignment. Phylogenetic tree analysis of amino-acid sequences deduced from SCDR10B, HSD11B1 and HSD11B2 was performed using the bootstrap neighbor-joining method with 1000 replicates (Felsenstein, 1985). GenBank accession numbers of previously known HSD11B1, HSD11B2, the novel SCDR1OB and its homologs' sequences used for analysis are HSD11B1: human (NP_861420), monkey (AAB27374), dog (NP_001005756), pig (NP_999413), cat (AAN40687), mouse (NP_032314), sheep (NP_001009395), rat (NP_ 058776), guinea pig (AAS47491), frog (AAH54291). HSD11B2: human (NP_000187), cattle (NP_777067), sheep (NP_001009460), rabbit (P51976), horse (AAD31186), mouse (NP_032315), rat (NP_058777), pig (NP_999078), frog (AAH74144), zebrafish (NP_997885), Nile tilapia (AAO42610), rainbow trout (BAC76709). SCDR10B: human (NP_941995), macaque (AAS68529), cattle (NP_996852), chicken (NP_001001201), zebrafish (AAS89256), stickleback (AAS89257), frog (AAI06473), medaka (AAS89258), seasquirt (AK116129), pimephalas (DQ862062), wheat (DQ862061), pine (DQ832430), sesame (AAL13315), cress (NP_680418).

Northern blot analysis of SCDR10B. Premade Multiple Tissue Northern (MTN) Blots of RNA isolated from eight human tissues (brain, heart, liver, lung, spleen, stomach, testis, skeletal muscle) were obtained from Shen Zhen King Grace Biotechnologies, Inc. (China). The blot was probed with $\left[\alpha{ }^{-32} \mathrm{P}\right] \mathrm{dCTP}-$ labeled complete coding region of human SCDR10B cDNA. Hybridization was performed according to the manufacturer's recommendations. Briefly, hybridization was carried out with $5 \times$ SSC, $5 \times$ Denhardt's, 10\% dextran sulfate, and denatured human DNA at $42^{\circ} \mathrm{C}$ overnight. After hybridization, the blots were washed three times at $42^{\circ} \mathrm{C}$ in $2 \times$ SSC containing $0.1 \%$ SDS for $15 \mathrm{~min}$ and twice in $0.1 \times$ SSC and $0.1 \%$ SDS at $42^{\circ} \mathrm{C}$ for $15 \mathrm{~min}$, and then subjected to autoradiography at $-80^{\circ} \mathrm{C}$. The blots were stripped by incubating for $10 \mathrm{~min}$ in $0.1 \times$ SSC and $0.5 \%$ SDS at $95^{\circ} \mathrm{C}$. The membranes were reprobed with radio-labeled $\beta$-actin as an indicator of RNA loading.

Tumor cell culture and RT-PCR. Seven human tumor cell lines (SGC7901, stomach cancer; H1299, lung adenocarcinoma in which p53 is not expressed; K562, leukemia; SPCA-1, lung adenocarcinoma; H446, small cell lung cancer; H460, large cell lung carcinoma; SHG-44, neuroglioma) were purchased from ATCC (USA) and were cultured as previously reported (Huang et al., 2004). Total RNA was extracted from seven different tumor cell lines with a single-step isolation method using TRIzol reagent according to the manufacturer's instructions. cDNA was synthesized using $2 \mu \mathrm{g}$ of total RNA, Superscript II reverse transcriptase (Gibco BRL) plus oligo(dT) 15 (Promega) according to the manufacturer's protocols. First-strand cDNA was subjected to RT-PCR amplification on an FS-918 DNA Amplifier (Shanghai Fusheng Institute of Biotechnology, China) using the primer pair of SCDR10B-RT-A (5'TCTTCTACATCGCGGCGGACATG-3' corresponding to nucleotides 464-486) and SCDR10B-RT-B (5'CCGCCGAGTAGGGAGTGGAGAAC-3' corresponding to nucleotides 741-763). PCR product size was $300 \mathrm{bp}$. The expression of the $\beta$-2-microglobulin ( $\beta$ MG; GeneID: 567) was analyzed as a control: sense primer (5'-CTCGTGCTACTCTCTCTTTC-3'), antisense primer (5'-CATGTCTCGATCCCACTTAAC$\left.3^{\prime}\right)$. The PCR conditions were the same as in cloning except that the elongation time was changed to $30 \mathrm{~s}$.

Prokaryotic expression and purification. The SCDR10B coding sequence was generated by PCR amplification using $P f u$ polymerase (Stratagene Clon- 
ing Systems, La Jolla, CA, USA). The primers used to generate the sequence were: SCDR10B-pET32aA: (5'-GCCGAATTCATGAAGGTGCTTCTCCTC-3') containing an EcoRI restriction site and SCDR10BpET32a-B: (5'-ATACTCGAGGGCTGCGCGGCCGTGAC-3') containing an Xholl restriction site. The PCR product was digested with restriction enzymes EcoRI and XholI, and the resulting product was ligated into the EcoRI/XholI restriction site of the pET32a vector. The obtained sequence of the construct was verified by automated DNA sequencing. Bacterial overexpression was performed with Escherichia coli strain BL21 (DE3). After transformation of the plasmid construct obtained in E. coli and plating on LB-agar (100 mg/ml ampicillin), a single clone was used to inoculate a $5 \mathrm{ml}$ culture in LB-medium (200 $\mathrm{mg} / \mathrm{ml}$ ampicillin), and the cells were grown at $37^{\circ} \mathrm{C}$ overnight. They were then inoculated into $500 \mathrm{ml}$ of medium, and grown at $37^{\circ} \mathrm{C}$ until OD595 between 0.6 and 0.8. Overexpression of recombinant human SCDR10B was induced by adding IPTG to a final concentration of $0.3 \mathrm{mM}$ and cells were incubated at $25^{\circ} \mathrm{C}$ for an additional $5 \mathrm{~h}$. The cells were harvested by centrifugation at $10000 \times g$ for $15 \mathrm{~min}$, resuspended in lysis buffer, and then split by adding lysozyme to buffer. After a short period of ultrasonic action on ice, insoluble cell debris was removed by centrifugation at $12000 \times \mathrm{g}$ for $45 \mathrm{~min}$ twice at $4^{\circ} \mathrm{C}$. The soluble extract was loaded onto Ni-NTA His-bind resin equilibrated with $1 \times \mathrm{Ni}$-NTA bind buffer (Novagen), washed with $2 \times 20 \mathrm{ml} 1 \times \mathrm{Ni}-\mathrm{NTA}$ wash buffer, then the protein was eluted with $4 \times 0.5 \mathrm{ml} 1 \times \mathrm{Ni}-\mathrm{NTA}$ elution buffer. The cell pellet and the eluted fractions were collected and analyzed by SDS/PAGE.

In vitro hydroxysteroid dehydrogenase activity assay. The activity of SCDR10B was measured with cortisol and cortisone as substrates (Ozols, 1995). The activities were assayed at $26^{\circ} \mathrm{C}$ by measuring the absorbance change at $340 \mathrm{~nm}$ in 5 min using spectrophotometer (U-3000, Hitachi). The molar absorption coefficient used for calculating rates is $6220 \mathrm{M}^{-1} \mathrm{~cm}^{-1}$. A standard assay mixture for dehydrogenation reactions contained $20 \mathrm{mM}$ Tris $/ \mathrm{HCl}$ (pH 8.5), $250 \mu \mathrm{M} \mathrm{NADP}{ }^{+}\left(\mathrm{NAD}^{+}\right), 0-100 \mu \mathrm{M}$ cortisol substrate, and appropriate quantities of SCDR10B protein. When the reduction reaction was measured, the $\mathrm{pH}$ of Tris/ $\mathrm{HCl}$ was adjusted to 7.0 , and the cortisol substrate was replaced with cortisone, and $250 \mu \mathrm{M}$ NADPH (NADH) was used as a cofactor.

Rabbit anti human SCDR10B polyclonal antibody preparation and immunohistochemistry. Anti-SCDR10B antibodies were raised by immunizing rabbits with purified SCDR10B protein. Tissues were obtained from the Department of Pathology, Suzhou Medical College (Suzhou, China). In every case, tissues had been obtained from operative samples in accordance with local ethical committee ap- proval. Five-micron thick formalin-fixed sections of normal cerebrum, hippocampus, cerebellar glioma and meningioma were cut and placed on coated glass slides. After dewaxing, slides were treated with $3 \%$ hydrogen peroxide for $10 \mathrm{~min}$ to block endogenous peroxidase activity. After washing in phosphate-buffered saline (PBS, $0.01 \mathrm{~mol} / \mathrm{l}, \mathrm{pH} 7.2$ ), goat serum was used to block for $15 \mathrm{~min}$ at $37^{\circ} \mathrm{C}$, and then slides were incubated with polyclonal antibody to human SCDR10B at a dilution of 1:300; omission of primary antibody was used as a control. A secondary antibody, goat anti-rabbit IgG biotin conjugated $(1: 100)$, was added to the sections for $20 \mathrm{~min}$. SABC was added and incubated for $15 \mathrm{~min}$, and slides were developed using 3,39'-diaminobenzidine and were counterstained with hematoxylin.

\section{RESULTS}

\section{Human SCDR10B gene and its genomic organization}

In order to clone the SCDR10B gene by PCR, we first analyzed the tissue distribution of the ESTs from SCDR10B. We found that many ESTs were transcribed from the brain, so a human brain cDNA library was used as a template for PCR amplification. We found that the PCR products included three bands with different sizes in the agarose gel. These bands were excised and cloned into a pMD18-T vector $(\mathrm{TaKaRa})$ and the clones were subjected to sequencing. The sequencing result indicated that these cDNAs were different alternative splicing product of the SCDR10 gene. These cDNA sequences were submitted to GenBank with the following GenBank accession numbers: SCDR10A, SCDR10B (short-chain dehydrogenases/reductases 10, isoform B AY268352), SCDR10C, SCDR10D, SCDR10E, SCDR10F and SCDR10G. The cDNA sequence of SCDR10B is consistent with the contig, and only the SCDR10B splice variant has a protein sequence similar to the whole coding region of $11 \beta-H S D 1$. SCDR10B is $1677 \mathrm{bp}$ in length, encoding a protein of 286 amino acids (Fig. 1). The molecular mass and isoelectric point are predicted to be $30.8 \mathrm{kDa}$ and $10.3 \mathrm{kDa}$, respectively, using Vector NT I software. SCDR10B is composed of eight exons and seven introns (Table 1). The open reading frame is from nucleotide 223 to nucleotide 1080. The ATG start codon (nucleotides 455-457) is preceded by an in-frame stop codon TGA, and there is a typical polyadenylation signal AATAAA. The protein contains two conserved motifs which all SDR family members have: one is GANAGVG (GXXXGXG), a motif which is related to binding $\operatorname{NAD}(\mathrm{P})(\mathrm{H})$, the other is YSAAK (YXXXK) which is related to its catalytic activity. SCDR10B was 


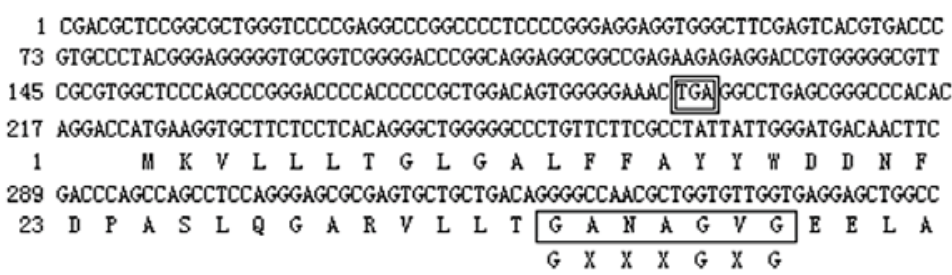

361 TATCACTACGCGCGTCTGGGCTCCCACCTGGTGCTCACTGCCCACACTGAGGCTCTCCTGCAGAGGTGGTA

47 Y H 433 GGGAACTGCCGGAAGCTGGSCGCCCCCAAGTCTTCTACATCGCGGCGGACATGGCCTCCCCTGAGGCGCCC $\begin{array}{lllllllllllllllllllllllll}71 & G & H & C & R & K & L & G & \text { A } & P & K & V & F & Y & I & \text { A } & \text { A } & D & \| I & \text { A } & S & P & E & \text { A } & P\end{array}$ 505 GAGAGCGTGGTGCAGTTTGCGCTGGACAAGCTGGGCGGGCTGGACTACCTCGTGCTGACCACATCGGCGGC

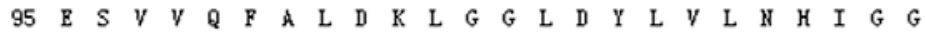
577 GCCCCGGCCGGCACGCGAGCCCGCAGCCCCCAGGCACTCGCTGGCTCATGCAGGTAHACTTTGTGAGCTAC 119 \& $P$ \& $G \quad T$ $R$ A 649 GTGCAACTGACGTCGCGGGCGCTGCCCAGCCTGACGGACAGCAAGGGCTCCCTGGTGGTGGTGTCCTCGCTG

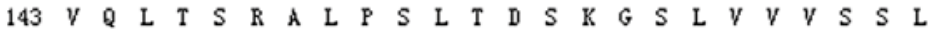
721 CTCGGCCGCGTGCCCACGTCGTTCTCCACTCCCTACTCGGCGGCCAGTTTTCGCTGGACGGCTTCTTCGGC

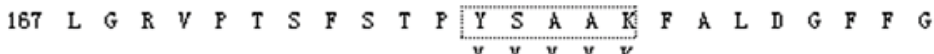

793 TCCCTGCGGCGGGAGCTGGACGTGCAGGACGTGAACGTGGCCATCACCATGTGCGTCCTGGGCCTCCGAGAT

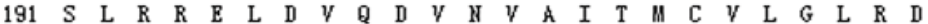
865 CGCGCCTCCGCCGCCGAGGCAGTCAGGGGAGTCACGAGGGTCAAGGCGGCCCCGGGGCCCAAGGCAGCCCTG

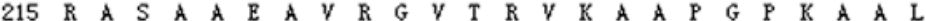
937 GCCGTGATCCGCGGCGGCGCCACGCGCGCGGCCGGCGTCTTCTACCCGTGGCGTTTCCGCCTGCTGTGCTTG $\begin{array}{llllllllllllllllllllllllll}239 & \text { मे } & V & I & R & G & G & \text { मे } & T & R & \text { मे } & \text { मे } & G & V & F & Y & P & \text { hy } & R & F & R & L & L & C & L\end{array}$ 1009 CTCCGGCGCTGGCTACCGCGCCCGCGGGCCTGGTTTATCCGCCAGGAGCTCAACGTCACGGCCGCGGCAGCC

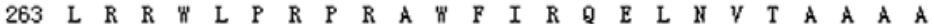
1081 TGAGCACCGGGGGGTGCCCCTCCAGTCCCAGACGGCATGTTCCTCCCTCCAACTGTCCCTGGAGCCAGAAC $287 *$

1153 ACTCACAGAGACACCCCTGAGAGGGTGCCACAGCCCARGATGAGTCATCAHGACAGHhHGCAHACCGA 1225 GAHAACGACGGGCACCTGGAACCAGTCACGGCTTGGGAGGTGCAGGTGCCCCGTGTTAGGCGCCTTTGTCG 1297 GGGACTTGCAAGGCCTCACCTGITTGGCCAIGATTGATGACGTGACTGCTTCCATTTTGCAGATGAGGAHAC 1369 TAAGGTCAGAGAGGCCACGCCACCCTTGAGCCACCCATGGACCCCTCTCCATCTCCTGCCTGCGCCTTTAA

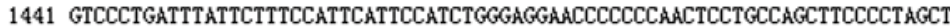
1513 GGGGTCTCTGGTACTCTTCACACCTGCAGGGGCGTCTACACTGTTCGTCTACCTGGTGGCAGGGTCTGAGCG 1585 GGAGGAGGAGGGAAGAGTGTGTTCTGAGCTGGACCCAGCCTCTTGTTCGAGAATAAAACTCTTCTTCTCT

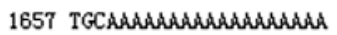

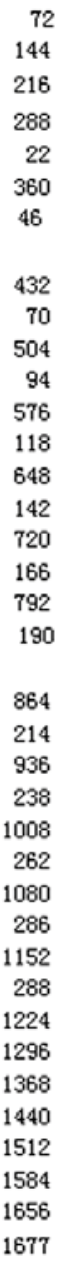

Figure 1. Nucleotide sequence and deduced protein sequence of the human SCDR10B gene.

SCDR10B encodes a polypeptide of 286 amino acid. Amino acids are identified by their one-letter code. Both nucleotides and amino acids are numbered at the left and right side of each line, respectively. * The termination codon TGA; AATAAA Polyadenylation signals; TGA, in-frame stop codon;

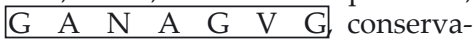
tive motif binding to co-factor $\mathrm{NAD}(\mathrm{P})(\mathrm{H})$; Y S A A K conservative motif related to its catalytic activity. mapped to chromosome 19p13.3 by browsing the UCSC genomic database (http://genome.ucsc.edu). Result of searching in SMART database showed that the SCDR10B protein contains a transmembrane helix and SDR_Short domain (http://smart.embl-heidelbeg.de).

\section{In silico clone of SCDR10B orthologs}

TBLASTN GenBank searches with the coding sequence of human SCDR10B protein allowed us to identify many ESTs in different species including monkey, cattle, chicken, frog, zebrafish, medaka, stickleback, wheat and loblolly pine. These ESTs were extracted and assembled into contigs in different species, and we obtained the cDNA sequences of the orthologs of SCDR10B in monkey, cattle, chicken, frog, zebrafish, medaka and stickleback, as well as the homologs of the $11 \beta$-hydroxysteroid dehydrogenase family in the plants (wheat, loblolly pine). All the cDNA sequences encoding the protein with the whole ORF covered the whole human SCDR10B coding region. These sequences were submitted to GenBank with the accession numbers: monkey AY554048, cattle AY554049, chicken AY578179, ze- brafish AY578810, medaka AY578812, stickleback AY578181, pimephalas DQ862062, wheat DQ862061, loblolly pine DQ832430. To our surprise, a BLAST search of the mouse and rat genomes and the GenBank database with SCDR10B, we did not find any orthologs to human $S C D R 10 B$ in rodents. In addition, in a blast search of the GenBank database with $11 \beta-H S D 1$, we did not find any orthologs in fish.

A search of published protein databases for sequences similar to that of SCDR10B indicated that it had considerable similarity to the $11 \beta-H S D 1$ family. So SCDR10B is a new subgroup of the 11/-hydroxysteroid dehydrogenase family. This subgroup

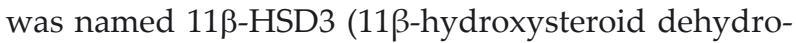
genase 3).

Multiple alignment analysis in Fig. 2a indicated that the orthologs of human SCDR10B are conserved in different species, the sequence identities of each ortholog to human SCDR10B is: $97 \%$ (macaque), 88\% (cattle), 57\% (chicken), 52\% (frog), 50\% (zebrafish), 52\% (stickleback), 49\% (medaka), $46 \%$ (pimephalas), 33\% (seasquirt), and the similarity of human SCDR10B and its orthologs is higher in the NADP-binding region and active site region than in the C-terminus. The C-terminal region is 
Table 1. Genomic structure of SCDR10B gene

\begin{tabular}{llllll}
\hline 3' Splice acceptor & Exon & $\begin{array}{l}\text { Size } \\
(\mathrm{bp})\end{array}$ & 5' Splice donor & $\begin{array}{l}\text { Intron } \\
(\mathrm{bp})\end{array}$ \\
\hline cDNA endCGACGCTCCG & 1 & 208 & GCCTGAGCGGgtgagtgcac & 1 & 3547 \\
cctctgcagTTCGACCCAG & 2 & 87 & TTCGACCCAGgtgagcacct & 2 & 83 \\
ctatggccagCCAGCCTCCA & 3 & 131 & CCTGCAGAAGgtgagccacc & 3 & 1296 \\
ccccccagGTGGTAGGGA & 4 & 112 & GACAAGCTGGgtgaggggct & 4 & 372 \\
tctgggccagGCGGGCTGGA & 5 & 91 & GCTCATGCAGgtgctccgct & 5 & 290 \\
ccgcctgcagGTAAACTTTG & 6 & 94 & TCGCTGCTCGgtgcgtgcac & 6 & 127 \\
gcgccccagGCCGCGTGCC & 7 & 166 & AGGCAGTCAGgtgaggcceg & 7 & 84 \\
ctgtccccagGGGAGTCACG & 8 & 770 & CTTCTCTTGCaaaaaaaaaa & polyA \\
\hline
\end{tabular}

Exon sizes are given in bp and the exonic and intronic sequences at the splice junction are shown in capital and lowercase letters, respectively. The exon-intron splicing signals gt and ag are in bold.

the steroid substrate binding region, which is obviously different between human SCDR10B and its fish homologs. All the members have conserved the YXXXK motif, but seasquirts do not have the conserved GXXXGXG motif.

Furthermore, we analyzed the evolutionary relationship among different $11 \beta$-hydroxysteroid dehydrogenase family proteins with bootstrap N-J tree analysis (Fig. 2b), which shows that human SCDR10B and its orthologs in different species except seasquirt cluster together. SCDR10B is one of the proteins conserved during evolution.

\section{Expression pattern of the SCDR10B gene}

Northern blotting and RT-PCR were used to determine the expression pattern of the gene. In order to investigate the tissue expression pattern of SCDR10B, Premade Multiple Tissue Northern (MTN) Blots including eight human tissues (brain, heart,

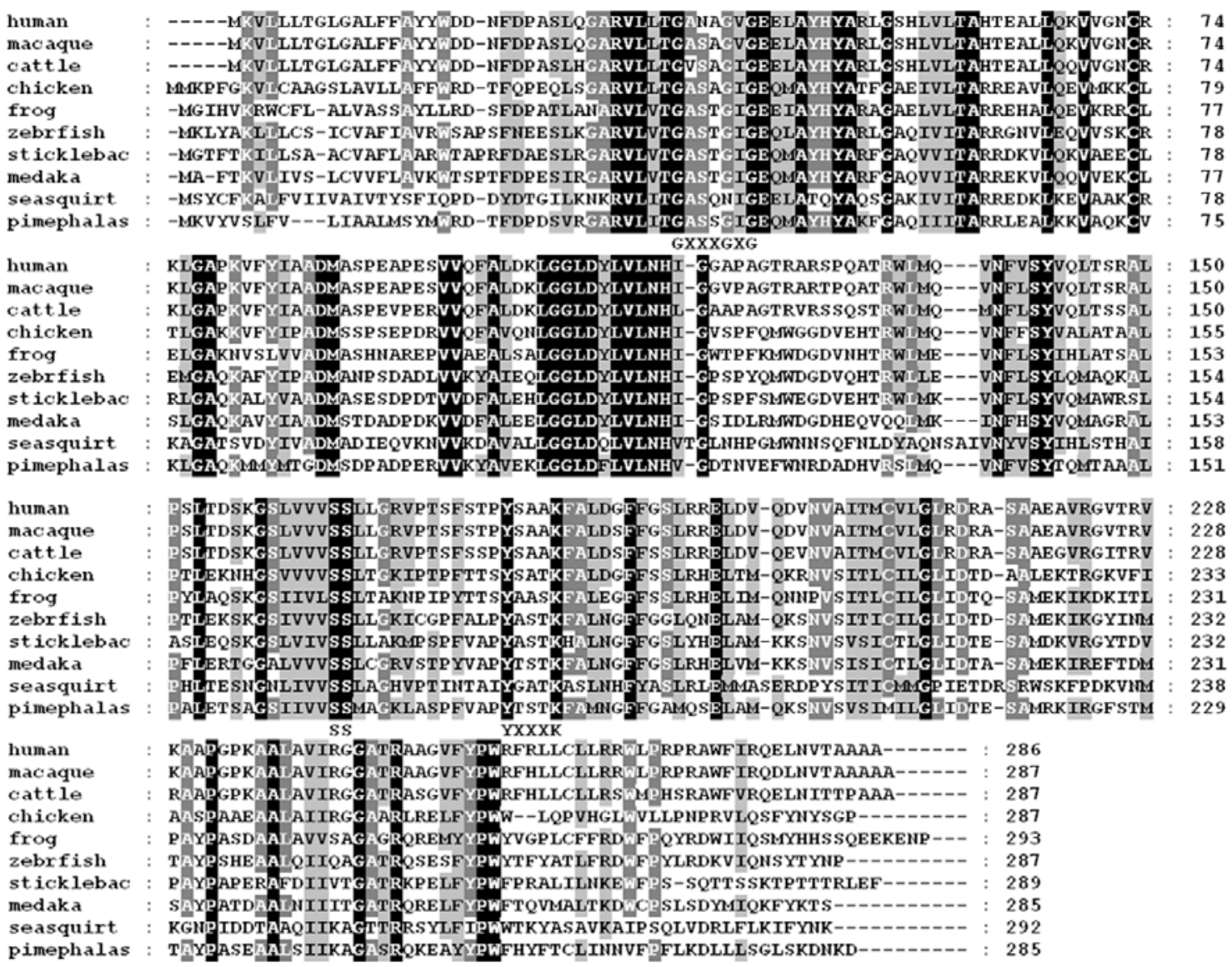

Figure 2a. Sequence alignments of human SCDR10B protein and its orthologs.

Identical amino acids are shaded in black, similar amino acids are shaded in grey. The sequences used for alignment include: human (NP_941995), macaque (AAS68529), cattle (NP_996852), chicken (NP_001001201), zebrfish (AAS89256), stickleback (AAS89257), frog (AAI06473), medaka (AAS89258), seasquirt (AK116129) and pimephalas (DQ862062). 


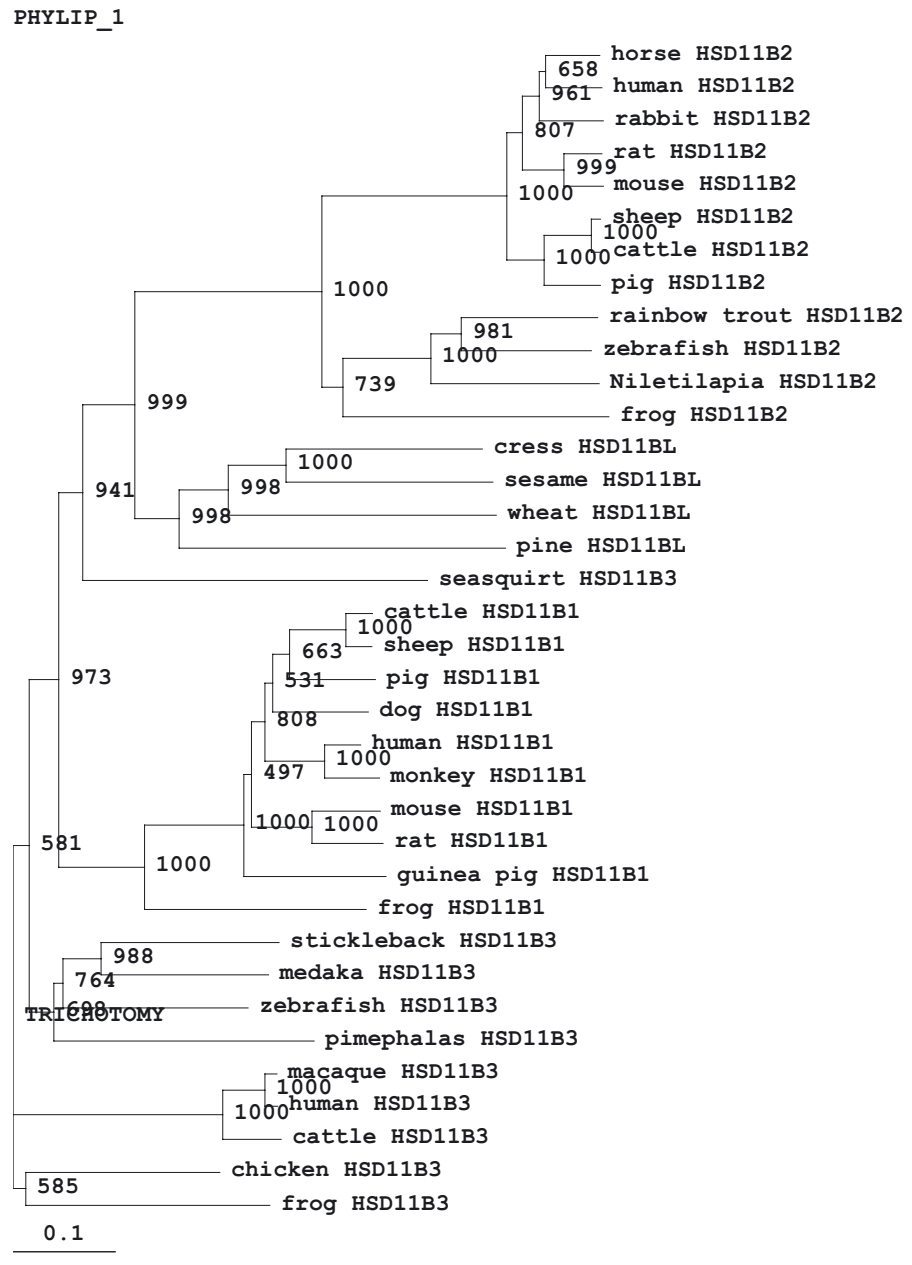

Figure $2 b$. Phylogenetic tree of $11 \beta$-hydroxysteroid dehydrogenase family members.

A phylogenetic tree was constructed with the bootstrap N-J method using program PHYLIP with 1000 bootstrap trials. The number is the value found in 1000 trials. liver, lung, spleen, stomach, testis, and skeletal muscle) were used for Northern blot analysis. The tissue distribution pattern of SCDR10B mRNA is shown in Fig. 3. The result revealed that $S C D R 10 B$ was highly expressed in brain, and low expression was detected in lung, spleen, stomach, testis, and skeletal muscle. The size of the transcripts was about $1.7 \mathrm{~kb}$. In heart and liver, almost no positive signal was detected. There are two isoforms of actin expressed in heart and muscle, so two bands observed in the control transcript ( $\beta$-actin).

RT-PCR analysis was used to determine the expression pattern of $S C D R 10 B$ mRNA in six tumor cell lines; the result in Fig. 4 showed that the SCDR10B gene was differentially expressed in these tumor cell lines. The expression level was higher in lung cancer cell lines SPCA-1, H460 and H446 than in stomach cancer cell line SGC7901, leukemia cell line K562 and neuroglioma cell line SHG-44.

\section{Expression and purification of recombinant SCDR10B protein in a prokaryote}

In order to obtain the SCDR10B protein for characterizing its enzyme activity and for raising

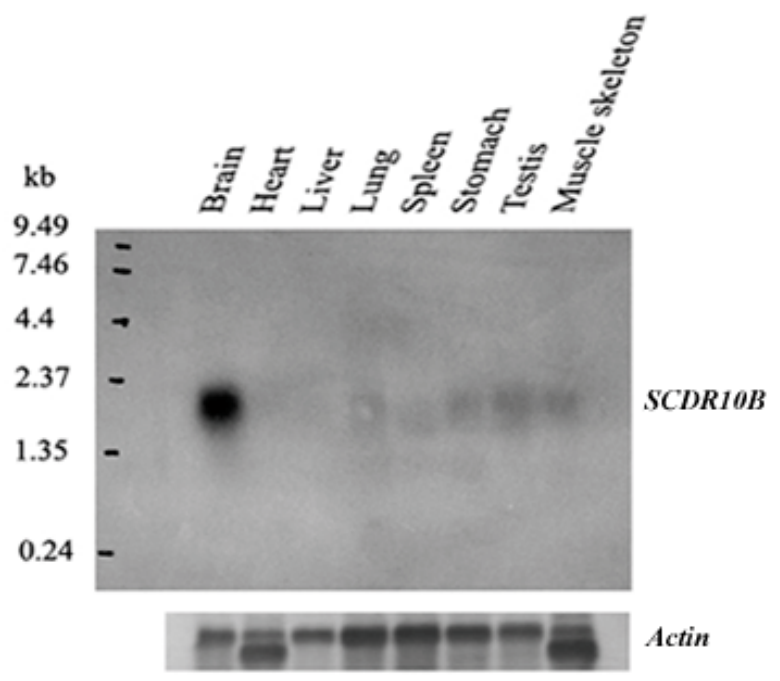

Figure 3. Northern blots analysis of $S C D R 10 B$ in human tissues.

A commercially available Northern blot membrane (Shen Zhen King Grace Biotechonologies, Inc., China) containing multiple human tissues (brain, heart, liver, lung, spleen, stomach, testis, skeletal muscle) was probed with a ${ }^{32} \mathrm{P}-\mathrm{la}-$ beled SCDR10B CDNA. The blot was stripped and reprobed with $\beta$-actin cDNA probe supplied with the blot to confirm equal loading of mRNA on the blot. A transcript of $1.7 \mathrm{~kb}$ was detected in the adult human brain tissue. 

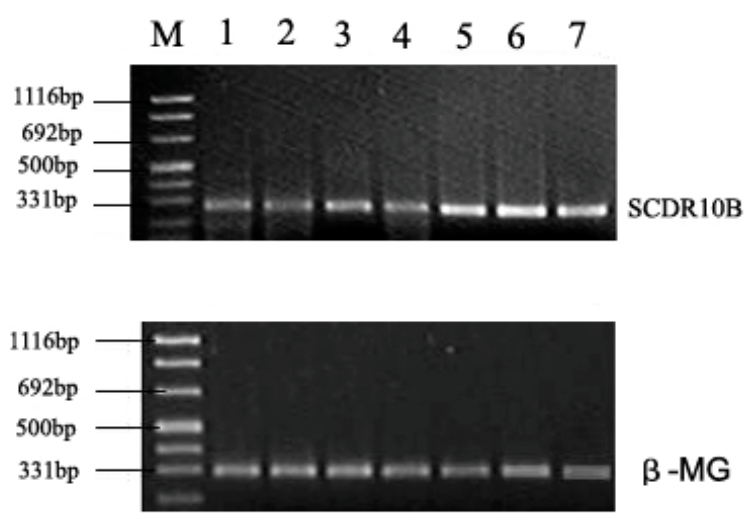

Figure 4. Expression pattern of $S C D R 10 B$ in seven human tumor cell lines.

Total RNA was extracted from seven different tumor cell lines with a single-step isolation method using TRIzol reagent. cDNA was synthesized using $2 \mathrm{mg}$ of total RNA, SuperscriptII reverse transcriptase (Gibco BRL) plus oligo(dT)15 (Promega). First-strand cDNA was subjected to RT-PCR amplification using the primer pair of SCDR10BRT-A (5'-TCTTCTACATCGCGGCGGACATG-3') and SCDR10B-RT-B (5'-CCGCCGAGTAGGGAGTGGAGAAC$\left.3^{\prime}\right)$. PCR product size was $300 \mathrm{bp}$. The expression of the $\beta$-microglobulin $(\beta-\mathrm{MG})$ was analyzed as a control: sense primer (5'-CTCGTGCTACTCTCTCTTTC- $\left.3^{\prime}\right)$, antisense primer (5'-CATGTCTCGATCCCACTTAAC-3'). M, DNA marker; lane 1, stomach cancer SGC7901; lane 2, leukemia K562; lane 3, neuroglioma SHG-44; lane 4, lung adenocarcinoma H1299 in which P53 is not expressed; lane 5, lung adenocarcinoma SPCA-1; lane 6, large cell lung carcinoma H460; lane 7, small cell lung cancer H446.

rabbit anti-human SCDR10B polyclonal antibody, a SCDR10B-pET32a construct was transformed into E. coli strain BL21 (DE3). Recombinant SCDR10B protein was highly expressed after induction by 0.3 mM IPTG. We obtained high-purity SCDR10B protein by Ni-NTA His-Bind Resin affinity chromotography (Fig. 5).

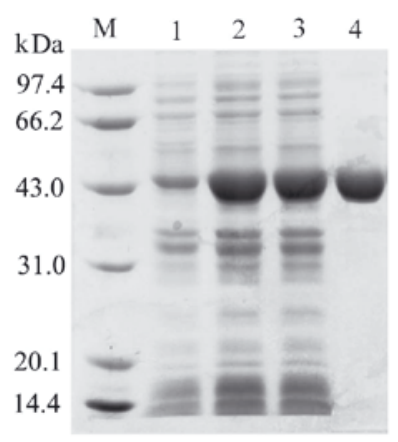

Figure 5. Expression of recombinant SCDR10B in E. coli strain BL21(DE3).

Coomassie Blue-stained SDS/PAGE gel of the SCDR10B expression construct. $\mathrm{M}$, molecular mass markers; lane 1, not induced by IPTG; lane 2 and 3, induced by adding IPTG to a final concentration of $0.3 \mathrm{mM}$; lane 4, purified SCDR10B protein.
Hydroxysteroid dehydrogenase activity assay

SCDR10B was a new member of the short chain dehydrogenase superfamily, and its enzyme activity was still unknown. Considering that it has a high sequence similarity to HSD11B1, we were interested in investigating whether SCDR10B is capable of catalyzing the dehydrogenation of cortisol and the reduction of cortisone in the presence of $\mathrm{NAD}(\mathrm{P})$ (H). Our result in Fig. 6 revealed that SCDR10B can catalyze the dehydrogenation of cortisol in the presence of $\mathrm{NADP}^{+}$. We also detected very weak activity in the presence of $\mathrm{NAD}^{+}$. Nevertheless, the rate of the reverse reaction, the reduction of cortisone, was not detected in our experiment (not shown).

Immunohistochemical analysis to investigate the tissue distribution of SCDR10B protein

SCDR10B was highly expressed in lung cancer cell lines (shown by RT-PCR), but only a weak expression was detected in normal lung (shown by Northern blotting), so we were interested in further investigating whether the expression of $S C D R 10 B$ is up-regulated in lung cancer. Immunohistochemical analysis was applied to determine the expression level of the SCDR10B protein in normal lung and cancerous lung; the result in Fig. 7a indicated that SCDR10B was highly expressed in cancerous lung. A strong staining signal was observed in lung cancer but only a weak signal was observed in normal lung.

Immunohistochemical analyses of human brain sections using SCDR10B polyclonal antibody indicated that SCDR10B was expressed in the cerebrum, hippocampal neurons, cerebellar glioma and meningioma (Fig. $7 \mathrm{~b}$ ). A strong staining signal was detected in the superficial layer of the cerebral cor-

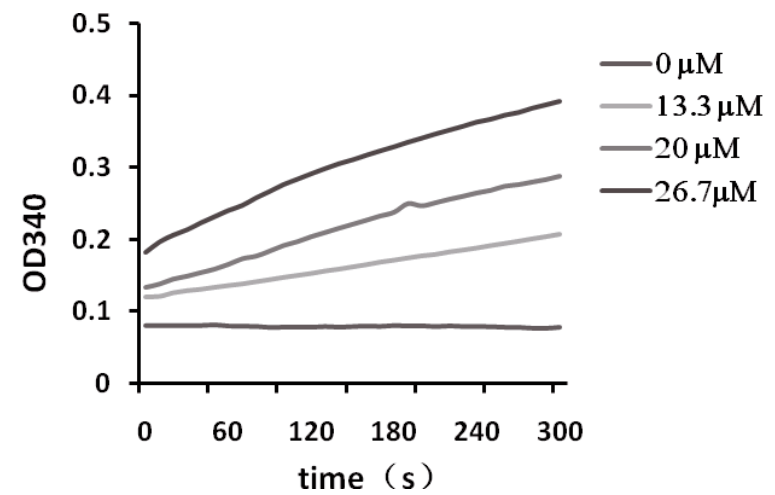

Figure 6. Time scan at $\mathrm{OD}_{340}$ analyzing the enzyme activity of SCDR10B.

Assay mixture for dehydrogenation reactions contained 20 $\mathrm{mM}$ Tris $/ \mathrm{HCl}(\mathrm{pH} 8.5), 250 \mu \mathrm{M} \mathrm{NADP}^{+}\left(\mathrm{NAD}^{+}\right), 0-100 \mu \mathrm{M}$ cortisol substrate, and appropriate quantities of SCDR10B protein. The concentration of cortisol from bottom to top is $0,13.3,20,26.7 \mu \mathrm{M}$. 
A

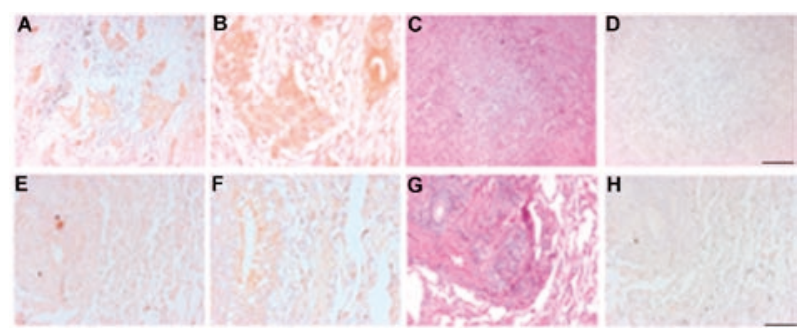

B

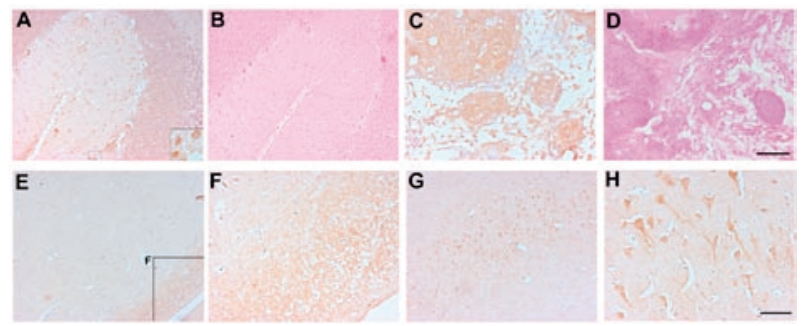

Figure 7a. Representative immunohistochemistry images depicting SCDR10B protein expression in normal lung and lung cancer.

A, B, C and D: expression of SCDR10B-immunoreactive protein in a section of human lung cancer; E, F, G and H: expression of SCDR10B-immunoreactive protein in a section of human normal lung. The image of $\mathrm{A}, \mathrm{B}, \mathrm{D}, \mathrm{E}, \mathrm{F}$ and $\mathrm{H}$ was developed by horse-radish peroxidase coupled goat anti-rabbit IgG staining. The image of $C$ and $G$ was developed by hematoxylin-eosin staining. A, E, D and H: $\times 10$ magnification. B and F: $\times 40$ magnification. A, B, C, E, F and G are a group of sections stained with the antihuman SCDR10B antibody at a dilution of 1:300. Omission of primary antibody was used as a control in panels $\mathrm{D}$ and $\mathrm{H}$. The thickness of the sections is $4 \mu \mathrm{M}$. Scales bar $10 \mu \mathrm{M}$.

Figure $7 \mathrm{~b}$. Representative immunohistochemistry images depicting SCDR10B protein expression in normal cerebrum, hippocampus, cerebellar glioma and meningioma.

A. B: expression of SCDR10B-immunoreactive protein in a section of human cerebellar glioma: A $\times 40$ magnified region was showed in panel A; C, D: expression of SCDR10B-immunoreactive protein in a section of human meningioma; E, F: expression of SCDR10B-immunoreactive protein in a section of human normal cerebral corex; G, H: Expression of SCDR10B-immunoreactive protein in a section of human hippocampus. The image of B and D was developed by HE staining. F: $\times 40$ magnified region was showed in panel E. H: $\times 40$ magnification of G. Scales bar $10 \mu \mathrm{M}$.

tex. Hippocampal neurons also displayed strong staining. Strong and diffuse staining is observed in cerebellar glioma and meningioma.

\section{DISCUSSION}

In the present study, we report the isolation and characterization of a novel human short-chain dehydrogenase/reductase gene SCDR10B, which maps to chromosome 19p13.3. It contains an ORF with length of $858 \mathrm{bp}$, encoding a protein with a short-chain dehydrogenase/reductase (SDR) domain. The SDR superfamily is a very large family consisting of more than 3000 members (Kallberg et al., 2002). Analysis of sequence similarities revealed that SCDR10B shares homology with $11 \beta$-hydroxysteroid dehydrogenase family members. The result of an enzyme activity assay revealed that SCDR10B can catalyze the dehydrogenation of cortisol in the presence of $\mathrm{NADP}^{+}$. Therefore it is a hydroxysteroid dehydrogenase.

$11 \beta$-HSD1 is highly expressed in the liver and adipose tissue, and is called "liver type" $11 \beta$ hydroxysteroid dehydrogenase. 11ß-HSD2 is highly expressed in the classical mineralocorticoid selective target tissues such as kidney, colon and sweat glands, and is called "kidney type" $11 \beta$-hydroxysteroid dehydrogenase. In contrast, the result of Northern blotting revealed that $S C D R 10 B$ is highly expressed in the brain. Immunohistochemical analysis of human brain sections using SCDR10B polyclonal antibody revealed that SCDR10B was transcribed in the cerebrum, hippocampal neurons, cerebellar glioma and meningioma. These results suggest that SCDR10B is a "brain type" hydroxysteroid dehydrogenase.

SCDR10B was a highly conserved protein during evolution. Its homologs were widely found in different species including animals and plants (Baker, 2004). Its orthologs were cloned in mammals (monkey, cattle), aves (chicken), fish (zebrafish, medaka, stickleback, pimephales) and ascidiacea (sea squirt). Blast analysis also indicated that wheat, loblolly pine, sesame, arabidopsis and Oryza sativa have homologs to SCDR10B and HSD11B1. The ortholog in sesame is called steroleosin; it was previously determined that steroleosin exerts dehydrogenase activity on both $17 \beta$-hydroxysteroid (estradiol) and $11 \beta$-hydroxysteroid (corticosterone) substrates in the presence of $\mathrm{NADP}^{+}$(Lin et al., 2002). Our results also indicated that SCDR10B exerts dehydrogenase activity on the cortisol substrate in the presence of $\mathrm{NADP}^{+}$. SCDR10B has a higher dehydrogenase activity in the presence of $\mathrm{NADP}^{+}$than in the presence of $\mathrm{NAD}^{+}$. The sequence similarity of human SCDR10B and its orthologs is higher in the NADP-binding region and active site region than at the C-terminus. The C-terminal region is the steroid binding region, which is obviously different beween human SCDR10B and its homologs, which suggests that SCDR10B is likely to metabolize different substrates in mammals, fish, chicken, seasquirt and plants. Elucidating their catalytic mechanisms is needed in a future study. 
Abnormal hormone signaling and action is a main feature in the pathogenesis of major cancers afflicting western populations (Henderson \& Feigelson, 2000). For instance, breast cancer is linked to estrogen and progesterone, prostate cancer is associated with estrogen and testosterone, endometrial cancer is linked to estrogen, and thyroid cancer is linked to thyroid hormones and thyroid stimulating hormone. In contrast, the role of glucocorticoids in the pathophysiology and treatment of cancers is less known. Glucocorticoids inhibit the proliferation of many cell types. Reductase activity of $11 \beta$-HSD1 increases local cortisol levels and leads to increased differentiation (Bujalska et al., 2002a; 2002b). The dehydrogenase activity of $11 \beta-H S D 2$ decreases the availability of active cortisol thereby facilitating proliferation (Rabbitt et al., 2003). It was reported that $11 \beta$-HSD2 is upregulated in different tumors, including breast cancer (Cohen, 2005; Koyama et al., 2001), colorectal cancer (Zbankova et al., 2004), and pituitary adenoma (Nigawara et al., 2006), which suggests that the inhibition of $11 \beta-H S D 2$ activity can prevent the tumor from growing. The results of RT-PCR indicated that the expression of SCDR10B in lung cancer cell lines is upregulated; in agreement with this, immunohistochemical analysis also showed that $S C D R 10 B$ is transcribed in the cancerous lung at a higher level than in normal lung tissue, which suggests that the abnormal expression of SCDR10B in the lung maybe related to the development of lung cancer.

\section{Acknowledgements}

The authors are grateful to Mr. Kevin Fortin in University of Florida (USA) for his help with correcting the English language.

\section{REFERENCES}

Arriza JL, Simerly RB, Swanson LW, Evans RM (1988) The neuronal mineralocorticoid receptor as a mediator of glucocorticoid response. Neuron 1: 887-900.

Audige A, Dick B, Frey BM, Frey FJ, Corman B, Vogt B (2002) Glucocorticoids and 11ß-hydroxysteroid dehydrogenase type 2 gene expression in the aging kidney. Eur J Clin Invest 32: 411-420.

Baker ME (2004) Evolutionary analysis of $11 \beta$-hydroxysteroid dehydrogenase-type 1, -type 2, -type 3 and 17betahydroxysteroid dehydrogenase-type 2 in fish. FEBS Lett 574: 167-170.

Brereton PS, van Driel RR, Suhaimi F, Koyama K, Dilley R, Krozowski Z (2001) Light and electron microscopy localization of the $11 \beta$-hydroxysteroid dehydrogenase type I enzyme in the rat. Endocrinology 142: 1644-1651.

Bujalska IJ, Walker EA, Hewison M, Stewart PM (2002a) A switch in dehydrogenase to reductase activity of $11 \beta-$ hydroxysteroid dehydrogenase type 1 upon differentiation of human omental adipose stromal cells. J Clin Endocrinol Metab 87: 1205-1210.
Bujalska IJ, Walker EA, Tomlinson JW, Hewison M, Stewart PM (2002b) 11ß-hydroxysteroid dehydrogenase type 1 in differentiating omental human preadipocytes: from de-activation to generation of cortisol. Endocr Res 28: 449-461.

Cohen PG (2005) Estradiol induced inhibition of 11 $\beta$-hydroxysteroid dehydrogenase 1: an explanation for the postmenopausal hormone replacement therapy effects. Med Hypotheses 64: 989-991.

De Kloet ER, Van Acker SA, Sibug RM, Oitzl MS, Meijer OC, Rahmouni K, de Jong W (2000) Brain mineralocorticoid receptors and centrally regulated functions. Kidney Int 57: 1329-1336.

Diaz R, Brown RW, Seckl JR (1998) Distinct ontogeny of glucocorticoid and mineralocorticoid receptor and $11 \beta$ hydroxysteroid dehydrogenase types I and II mRNAs in the fetal rat brain suggest a complex control of glucocorticoid actions. J Neurosci 18: 2570-2580.

Felsenstein J (1985) Confidence limits on phylogenics: an approach using the bootstrap. Evolution 39: 783-791.

Filling C, Berndt KD, Benach J, Knapp S, Prozorovski T, Nordling E, Ladenstein R, Jornvall H, Oppermann UC (2002) Critical residues for structure and catalysis in shortchain dehydrogenases/reductases. J Biol Chem 277: 25677-25684.

Funder JW (2005) Mineralocorticoid receptors: distribution and activation. Heart Fail Rev 10: 15-22.

Henderson BE, Feigelson HS (2000) Hormonal carcinogenesis. Carcinogenesis 21: 427-433.

Huang CQ, Zhou JL, Wu SL, Shan YX, Ten SL, Yu L (2004) Cloning and tissue distribution of the human B3GALT7 gene, a member of the $\beta 1,3-$ glycosyltransferase family. Glycoconj J 21: 267-273.

Jornvall H, Persson B, Krook M, Atrian S, Gonzalez-Duarte R, Jeffery J, Ghosh D (1995) Short-chain dehydrogenases/reductases (SDR). Biochemistry 34: 6003-6013.

Kallberg Y, Oppermann U, Jornvall H, Persson B (2002) Short-chain dehydrogenase/reductase (SDR) relationships: a large family with eight clusters common to human, animal, and plant genomes. Protein Sci 11: 636-641.

Kataoka S, Kudo A, Hirano H, Kawakami H, Kawano T, Higashihara E, Tanaka H, Delarue F, Sraer JD, Mune T, Krozowski ZS, Yan K (2002) 11 $\beta$-hydroxysteroid dehydrogenase type 2 is expressed in the human kidney glomerulus. J Clin Endocrinol Metab 87: 877-882.

Kotelevtsev Y, Brown RW, Fleming S, Kenyon C, Edwards CR, Seckl JR, Mullins JJ (1999) Hypertension in mice lacking 11ß-hydroxysteroid dehydrogenase type 2. J Clin Invest 103: 683-689.

Koyama K, Myles K, Smith R, Krozowski Z (2001) Expression of the $11 \beta$-hydroxysteroid dehydrogenase type II enzyme in breast tumors and modulation of activity and cell growth in PMC42 cells. J Steroid Biochem Mol Biol 76: 153-159.

Krozowski ZS, Stewart PM, Obeyesekere VR, Li K, Ferrari P (1997) Mutations in the 11 $\beta$-hydroxysteroid dehydrogenase type II enzyme associated with hypertension and possibly stillbirth. Clin Exp Hypertens 19: 519-529.

Lin LJ, Tai S, Peng CC, Tzen J (2002) Steroleosin, a sterolbinding dehydrogenase in seed oil bodies. Plant Physiol 128: 1200-1211.

Lin-Su K, Zhou P, Arora N, Betensky BP, New MI, Wilson RC (2004) In vitro expression studies of a novel mutation delta299 in a patient affected with apparent mineralocorticoid excess. J Clin Endocrinol Metab 89: 2024-2027.

Nigawara T, Iwasaki Y, Asai M, Yoshida M, Kambayashi M, Sashinami H, Hashimoto K, Suda T (2006) Inhibi- 
tion of $11 \beta$-hydroxysteroid dehydrogenase eliminates impaired glucocorticoid suppression and induces apoptosis in corticotroph tumor cells. Endocrinology 147: 769-772.

Oppermann UC, Filling C, Berndt KD, Persson B, Benach J, Ladenstein R, Jornvall H (1997) Active site directed mutagenesis of 3 beta/17 beta-hydroxysteroid dehydrogenase establishes differential effects on short-chain dehydrogenase/reductase reactions. Biochemistry 36: 34-40.

Ozols J (1995) Lumenal orientation and post-translational modifications of the liver microsomal $11 \beta$-hydroxysteroid dehydrogenase. J Biol Chem 270: 10360.

Patel PD, Sherman TG, Goldman DJ, Watson SJ (1989) Molecular cloning of a mineralocorticoid (type 1) receptor complementary DNA from rat hippcampus. Mol Cell Endocrinol 3: 1877-1885.

Poletto R, Steibel JP, Siegford JM, Zanella AJ (2006) Effects of early weaning and social isolation on the expression of glucocorticoid and mineralocorticoid receptor and $11 \beta$-hydroxysteroid dehydrogenase 1 and 2 mRNAs in the frontal cortex and hippocampus of piglets. Brain Res 1067: 36-42.

Rabbitt EH, Lavery GG, Walker EA, Cooper MS, Stewart PM, Hewison M (2002) Prereceptor regulation of glucocorticoid action by $11 \beta$-hydroxysteroid dehydroge- nase: a novel determinant of cell proliferation. FASEB J 16: 36-44.

Rabbitt EH, Gittoes NJ, Stewart PM, Hewison M (2003) $11 \beta$-hydroxysteroid dehydrogenases, cell proliferation and malignancy. J Steroid Biochem Mol Biol 85: 415-421.

Ricketts ML, Verhaeg JM, Bujalska I, Howie AJ, Rainey WE, Stewart PM (1998) Immunohistochemical localization of type $111 \beta$-hydroxysteroid dehydrogenase in human tissues. J Clin Endocrinol Metab 83: 1325-1335.

Stewart PM, Boulton A, Kumar S, Clark PM, Shackleton $\mathrm{CH}$ (1999) Cortisol metabolism in human obesity: impaired cortisone $\rightarrow$ cortisol conversion in subjects with central adiposity. J Clin Endocrinol Metab 84: 1022-1027.

Tomlinson JW, Bujalska I, Stewart PM, Cooper MS (2000) The role of 11ß-hydroxysteroid dehydrogenase in central obesity and osteoporosis. Endocr Res 26: 711-722.

Watzka M, Beyenburg S, Blumcke I, Elger CE, Bidlingmaier F, Stoffel-Wagner B (2000) Expression of mineralocorticoid and glucocorticoid receptor mRNA in the human hippocampus. Neurosci Lett 290: 121-124.

Wolf G (2002) Glucocorticoids in adipocytes stimulate visceral obesity. Nutr Rev 60: 148-151.

Zbankova S, Bryndova J, Kment M, Pacha J (2004) Expression of 11 $\beta$-hydroxysteroid dehydrogenase types 1 and 2 in colorectal cancer. Cancer Lett 210: 95-100. 